http://dx.doi.org/10.35381/r.k.v4i1.462

\title{
Diagnóstico situacional del potencial turístico de la parroquia Ricaurte, Azuay
}

\section{Situational diagnosis of the tourism potential of the parish Ricaurte, Azuay}

\author{
Diana Alexandra Padilla Campoverde \\ dpadillac@psg.ucacue.edu.ec \\ Universidad Católica de Cuenca \\ Ecuador \\ https://orcid.org/0000-0001-9553-5937
}

Juan Carlos Erazo Álvarez

jcerazo@ucacue.edu.ec

Universidad Católica de Cuenca

Ecuador

https://orcid.org/0000-0001-6480-2270

\author{
Cecilia Ivonne Narváez Zurita \\ inarvaez@ucacue.edu.ec \\ Universidad Católica de Cuenca \\ Ecuador \\ https://orcid.org/0000-0002-7437-9880
}

Recibido: 10 de agosto de 2019

Aprobado: 30 de agosto de 2019

\section{RESUMEN}

Se plantea como objetivo la elaboración de un diagnóstico situacional del potencial turístico dentro de la parroquia que promueve el desarrollo social y económico a través de la convivencia con las comunidades en la que podemos mostrar las riquezas que forman parte del patrimonio natural y cultural que caracterizan a cada pueblo. La metodología tuvo un diseño no experimental con un alcance descriptivo-explicativo. Los resultados manifiestan que Ricaurte es una parroquia competitiva que cuenta con la oferta necesaria para que los turistas se interesen por visitarla, pero con el apoyo incondicional de los moradores de cada comunidad o barrio se incentivaran programas de capacitación dentro de establecimientos que brinden servicios turísticos para mejorar su atención. Logrando de esta manera promocionar la identidad que caracteriza a Ricaurte, por medio de una campaña publicitaria en medios de comunicación, internet, páginas web, operadoras de turismo, entre otras.

Descriptores: Turismo; Diagnóstico; Comunidades; Estructura; Sistema. 


\begin{abstract}
The objective is the elaboration of a situational diagnosis of the tourism potential within the parish that promotes social and economic development through coexistence with the communities in which we can show the riches that are part of the natural and cultural heritage that characterize each town. The methodology had a non-experimental design with a descriptive-explanatory scope. The results show that Ricaurte is a competitive parish that has the necessary offer for tourists to be interested in visiting it, but with the unconditional support of the inhabitants of each community or neighborhood, training programs will be encouraged within establishments that provide tourist services for Improve your attention. Achieving in this way to promote the identity that characterizes Ricaurte, through an advertising campaign in the media, internet, web pages, tour operators, among others.
\end{abstract}

Descriptors: Tourism; Diagnosis; Communities; Structure; System

\title{
INTRODUCCION
}

El turismo es considerado uno de los mercados de crecimiento más rápido y competitivo en el mundo, por lo que cada país se preocupa por conseguir cada vez más turistas y agruparlos en un destino, para ello el turismo necesita proponer una evolución de marketing ya que el cliente de esta actividad tiene diferentes motivaciones para viajar (Idrovo, 2019). El turismo representa una actividad importante en el desarrollo de la economía del país, ya que se pretende que sea la primera fuente de ingreso de divisas en un largo plazo.

La Ministra de Turismo Rosi Prado de Holguín ha definido 5 hitos que son: la actualización de la ley orgánica de turismo, el plan estratégico de turismo del Ecuador 2030, la estrategia de promoción Ecuador, la evolución y posicionamiento de la marca país y el sistema de inteligencia de mercados y estadísticas. Estos marcan la gestión turística en el Ecuador en el año 2019, buscando de este modo coordinar de la mejor manera, el ministerio de turismo conjuntamente con todos los actores del turismo del país (Ministerio de Turismo, 2019).

La proyección de turismo para Ecuador en el 2018 se encuentra en auge, ya que el gobierno central al realizar la declaratoria de cielos abiertos brindo una gran oportunidad al país para que pueda mejorar en el desarrollo de las actividades del turismo y 
transporte aéreo tanto nacional como internacional, buscando a través de ellos una mejor conectividad con los turistas alrededor del mundo.

En el año 2017, el Ministerio de Turismo al realizar la Gran Feria Turística del Ecuador con el slogan "Ecuador, tu lugar en el mundo" buscaban lograr enamorar a todos los turistas del mundo de las bellezas que tiene el Ecuador, buscando de esta manera motivar a los ecuatorianos para que realicen un turismo interno, contando siempre con el apoyo de las instituciones públicas y la industria turística y de esa manera participen todos los ecuatorianos viajando los 365 días del año (Larrea, 2019).

Actualmente en la parroquia de Ricaurte de la Ciudad de Cuenca, debido a la falta de conocimiento de la existencia de atractivos turísticos naturales y culturales no se ha podido desarrollar la parroquia dentro del sistema turístico. Por lo tanto, hemos encaminado la propuesta de diseñar un Diagnostico de la estructura del sistema turístico de un destino, la cual permita tanto a los turistas nacionales y extranjeros a tener varias alternativas de diversión y esparcimiento dentro de la parroquia de Ricaurte, a través de ofertas de diferentes paradigmas de turismo como: Turismo de Aventura, Alternativo, Comunitario, Religioso, Gastronómico, Ancestral, entre otros.

Brindándole de esa manera al turista varios servicios en cuanto a paquetes turísticos, tours diarios, asesorías turísticas de calidad que conlleva: transporte, alojamiento, alimentación, actividades de esparcimiento, guías turísticos profesionales y extras dentro del entorno de la parroquia. Con la finalidad de incorporar a los inversionistas como un ente importante para la sociedad, logrando desplegar servicios de calidad turística que ayuden a mejorar la infraestructura dentro de la población y de esa manera generar ingresos rentables a los promotores.

Facilitando además, la promoción de los atractivos que existen dentro de la parroquia, a través de campañas publicitarias en diferentes medios de comunicación, de varias alternativas turísticas que se pueden desarrollar dentro de su entorno y así buscar satisfacer las necesidades propias y ajenas tanto del turista como de la población Ricaurtense. 


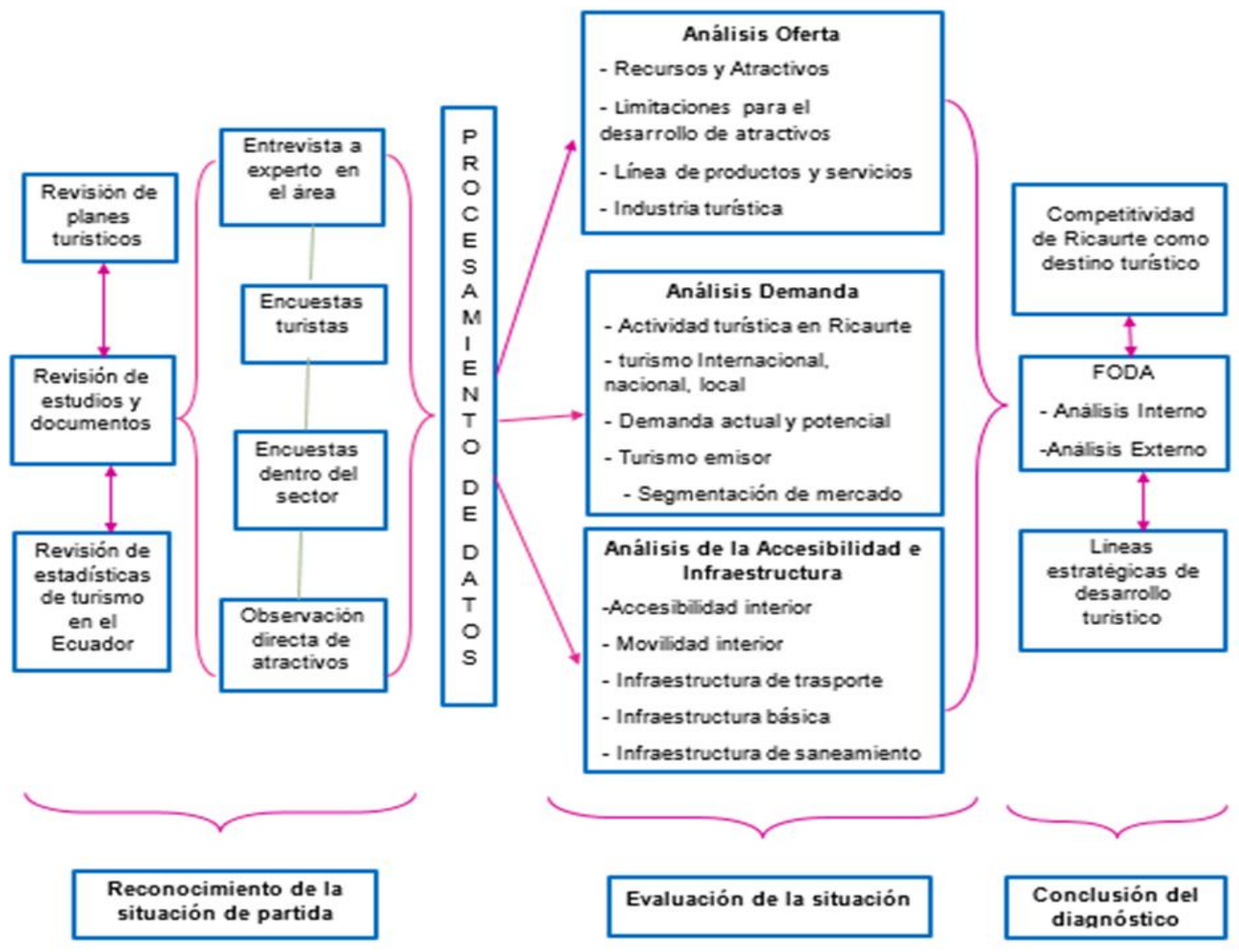

Figura 1. Diagnóstico General del Turismo en Ricaurte

Para evaluar el potencial turístico de un destino hay que evaluar 3 etapas primordiales dentro de la planificación, realizando primeramente el análisis de la situación turística existente, examinando de esta manera los recursos naturales y culturales, la oferta, la demanda, la competitividad y el mercado objetivo, para posteriormente elaborar el diagnostico comparando los resultados del análisis de la situación, permitiendo de esa manera identificar las fortalezas, oportunidades, debilidades y amenazas del destino y así finalmente poder definir estrategias a elaborarse como programas o proyectos para el desarrollo turístico en el destino (Blanco, 2008).

El diagnóstico turístico es la etapa de planificación en la que se adquiere información mediante la evaluación de la situación de un destino en tiempo real, permitiendo tomar decisiones acertadas con tácticas y una herramienta que contribuyera a evaluar el 
éxito o fracaso de los planes, programas o proyectos que establecerán el proceso de desarrollo dentro de la planificación turística.

Al diagnóstico también se lo conoce como línea base o estado de situación actual, buscando básicamente definir la situación en la que se encuentra el recurso o atractivo tanto natural como cultural del destino turístico, antes de que se establezca la planificación. Por lo tanto la finalidad del diagnóstico es definir la situación de los recursos y atractivos en tiempo real, analizando las oportunidades y limitaciones del territorio que se está analizando, fundamentando la toma de decisiones y las tácticas de desarrollo con datos cuantitativos y cualitativos restablecidos, finalmente establecer una línea base que nos permita elaborar una comparación entre la situación de los recursos antes y cuáles fueron los resultados obtenidos después de haber seleccionado las tácticas adecuadas de planificación turística (Ricaurte, 2009).

La elaboración de una metodología de diagnóstico implica elaborar varias etapas que permitirán el estudio de una manifestación determinada, ofreciendo elementos y recursos para evaluar la situación actual y a partir de ese análisis implementar tácticas que ayuden a mejorar los problemas encontrados, mejorando de esta manera su funcionamiento y contribución al logro de los objetivos de la comunidad (Vargas, 2010). El diagnostico turístico es un proceso técnico de investigación que engloba 3 etapas fundamentales para concluir con éxito la investigación mencionando como primera etapa el diseño del diagnóstico, la segunda etapa la recolección de información de campo y finalmente la tercera etapa de análisis y sistematización de resultados.

1. Etapa del diseño de diagnóstico: En esta etapa se define la manera en que va hacer recopilada la información de campo, incluyendo tres actividades que ayudaran en la planificación, determinando el enfoque y el tipo del diagnóstico que permitirá definir la metodología, recursos humanos, recursos económicos, tiempo y materiales necesarios para la recolección de la información pertinente en un proceso que se elabora dentro de la realidad del entorno y basado en los objetivos planteados, además se identifica la localización del sistema turístico a ser evaluado con la finalidad de 
determinar un espacio físico fácil de identificar en los mapas y sus coordenadas, asimismo se busca información adecuada del lugar que se está trabajando, esto se lo realiza antes de la recolección de información de campo para evitar contextualizarla información que se recogerá después.

2. Etapa de recolección de información de campo: Una vez terminada la primera fase de diagnóstico, se comienza a recolectar información de campo, a través de 3 fichas diseñadas para caracterizar los 6 elementos del sistema turístico local.

Los pasos a seguir en la etapa de recolección de información de campo son:

-Aplicación de la ficha de Caracterización Turística de la parroquia

-Aplicación de la ficha de Caracterización de Demanda

-Aplicación de la ficha de Caracterización de Recursos y Atractivos.

3. Etapa de análisis y sistematización de resultados: En esta fase se elabora el análisis de los tratamientos realizados en las diferentes fichas de diagnóstico que se desarrollaron para la parroquia de Ricaurte en la recolección de información.

La fase de análisis consiste en primero sistematizar todos los resultados obtenidos para posteriormente convertirlos en una base confiable para la posterior toma de decisiones basadas en diferentes herramientas (Ricaurte, 2009).

El funcionamiento del Sistema turístico empieza con la combinación de la oferta y la demanda turística por medio de un proceso de venta que le denominan producto turístico satisfaciendo las necesidades con el consumo de actividades turísticas, que a la vez conjuntamente con la infraestructura se forma la estructura de la producción del sector turístico (Boullón, 2006).

Según la OMT se analiza todos los elementos del sistema turístico para de esa manera determinar el potencial turístico del lugar, las limitaciones de crecimiento económico, segmentar el mercado objetivo, identificar los servicios y productos turísticos, logrando de esa manera resultados que nos ayuden a tomar el direccionamiento del plan y toma de decisiones. 
Se distinguen 4 elementos básicos dentro del concepto de la actividad turística que se analizan dentro del diagnóstico:

Oferta turística: Está compuesta por los productos, servicios y organizaciones involucradas activamente dentro del entorno turístico.

Demanda turística: Es la que está formada por consumidores y posibles consumidores de bienes y servicios que engloba la actividad turística.

Espacio geográfico: Es el lugar en el que se presenta situado la oferta conjuntamente con la demanda y en donde reside la comunidad ya que se considera un factor importante al momento de la planificación de la actividad turística.

Operadores del Mercado: Incluyen organismos y empresas con la finalidad de facilitar la relación entre la oferta y la demanda encontrándose aquí las agencias de viaje, operadoras de turismo, compañías de transporte y organismos públicos y privados que se encargan de velar por la promoción turística de un destino determinado (Sancho, 2017).

Otro aspecto que se da en el periodo de análisis del diagnóstico es la competitividad turística que adquiere el lugar, por lo tanto dentro del ámbito de la investigación turística se dice que es la capacidad que tiene un destino para crear productos o servicios con un valor añadido, en el que se puedan sostener los recursos locales y así conservar su posición de mercado con respecto a los consumidores (Alcocer, 2013).

Desde otro punto de vista la competitividad de un destino turístico se puede definir como la manera de ofrecer bienes y servicios a los excursionistas de forma que se sientan atraídos por el destino turístico mediante ofertas tentadoras haciéndolos que generen gasto de los turistas en el destino, satisfaciéndolos en sus necesidades y cumpliendo expectativas, consiguiendo con esto, que los turistas sean embajadores del destino. La competitividad debe aportar finalmente al bienestar social y económico. Asimismo el bienestar o prosperidad es la muestra de que el destino ha aumentado su competitividad logrando una mayor calidad de vida (Siles, 2016).

En base al plan de competitividad turística se diseña un mecanismo eficiente de promoción, un plan de mercadeo y un sistema de inteligencia de mercados en el que la 
promoción del Ecuador es clave dentro de los planes tanto sectoriales como regionales ya que la promoción turística, coincidiendo en estrategias de búsqueda de mercados objetivos, información profesional y un claro posicionamiento del Ecuador (Idrovo, 2019).

El Análisis FODA consiste en elaborar una evaluación de los factores tanto internos como externos, diagnosticando en conjunto la situación interna y la evaluación externa.

EI FODA es una herramienta sencilla pero muy importante ya que nos puede facilitar a tomar una perspectiva general de la situación estratégica de un destino determinado (Ponce, 2006).

Las estrategias de Turismo en el Ecuador están compuestas por programas, proyectos y actividades del Plan de Tour 2020, estas tienen aplicación nacional y regional con las adecuaciones pertinentes que se deben realizar según el diseño especifico del plan, resaltando que las estrategias determinadas son la suma de las propuestas de solución a los problemas encontrados dentro del sector turístico que se obtuvieron del análisis de los actores de cada región (Ministerio de Turismo, Ecuador, 2012). De ese modo, desde una proyección significativa se procede a elevar la calidad de los servicios prestados, (Aldana \& Piña, 2017), siendo esto pertinente en aras del crecimiento integral de la sociedad.

\section{METODOLOGÍA}

La presente investigación utilizó un diseño no experimental con enfoque mixto que se realizó en base a la recolección y análisis de información mediante datos cuantitativos y cualitativos. Su alcance fue descriptivo-explicativo, de la misma forma la finalidad de la investigación fue transversal a través de un análisis dentro de todos los ámbitos que fueron determinados en un solo momento del tiempo. Los métodos que se utilizaron fueron el inductivo-deductivo y el método histórico-lógico, que se logró, revisando la literatura objetiva permitiéndonos desarrollar el marco y el estado de la situación que sustentan esta investigación. (Ramón, Erazo, Narváez y Matovelle Romo, 2019) 
Para la recolección la encuesta, la entrevista y la observación con sus instrumentos cuestionario, guía de entrevista y fichas de guía de observación en la que se verifica la caracterización de los atractivos y recursos turísticos conjuntamente con la caracterización de la demanda y la caracterización turística de la parroquia de Ricaurte. El universo de estudio que obtuvimos fue de 197 elementos muestrales, los cuales se aplicaron en 196 encuestas y 1 entrevista.

\section{RESULTADOS}

\section{Diagnóstico de la Estructura del Sistema Turístico}

\section{Etapa de diseño del diagnóstico}

La etapa de planificación del diseño de diagnóstico del sistema turístico de la parroquia de Ricaurte, con la finalidad de recopilar información de campo se realizó encuestas, entrevistas y fichas de observación directa.

Estos instrumentos nos ayudaron en la recolección de información real consiguiendo verificar la caracterización turística de la parroquia, la demanda y la oferta de los atractivos y recursos turísticos. Puesto, que se definió realizar la planificación en espacios naturales, urbanos y rurales de la parroquia y de acuerdo a los potenciales turísticos identificados, los intereses de la demanda y la entidad planificadora, definimos una planificación con un enfoque económico, comunitario y sostenible.

Por lo tanto, esta planificación nos permitió ajustar el proceso de diagnóstico a la realidad del entorno y de esta manera ajustar los instrumentos para la recolección de información en base a los objetivos planteados.

\section{Etapa de recolección de información de campo:}

En esta etapa se comenzó a recolectar información de campo, a través de 3 fichas que se diseñaron para analizar la caracterización turística de la parroquia, la demanda y el inventario de los recursos y atractivos turísticos, conjuntamente con la elaboración de encuestas a turistas nacionales, extranjeros y locales que han visitado la ciudad de 
Cuenca para poder determinar nuestro público objetivo y entrevistas a dos expertos dentro del área de turismo que aportara en el análisis del diagnóstico turístico.

\section{Etapa de análisis y sistematización de resultados}

En esta etapa mostramos los resultados obtenidos del diagnóstico realizo en el trabajo de campo por lo que vamos a empezar describiendo algunos antecedentes con datos históricos y geográficos importantes de la parroquia.

La creación de esta parroquia fue obra de los ciudadanos: el sacerdote Isaac Antonio Chico y del musicólogo azuayo Luis Pauta Rodríguez, concediendo la parroquialización el 25 de marzo de 1910 y desmembrándola de la jurisdicción de Llacao.

Fue declarada parroquia civil en 1911 y en 1913 recibe el nombre del legendario héroe gran colombiano "Ricaurte". En 1914 cambia nuevamente la denominación por el de San Carlos de Ricaurte. La fundación de la parroquia tiene íntima relación con el aspecto religioso ya que perdura muy vivo entorno a un personaje eclesial como es el Padre Isaac Chico García.

Identificamos la localización del sistema turístico que fue evaluada, indicando por consiguiente, los límites de la parroquia de Ricaurte que son: Al norte con la parroquia Sidcay, al sur con la ciudad de Cuenca, al este con la parroquia de Llacao, al oeste con la ciudad de Cuenca. 


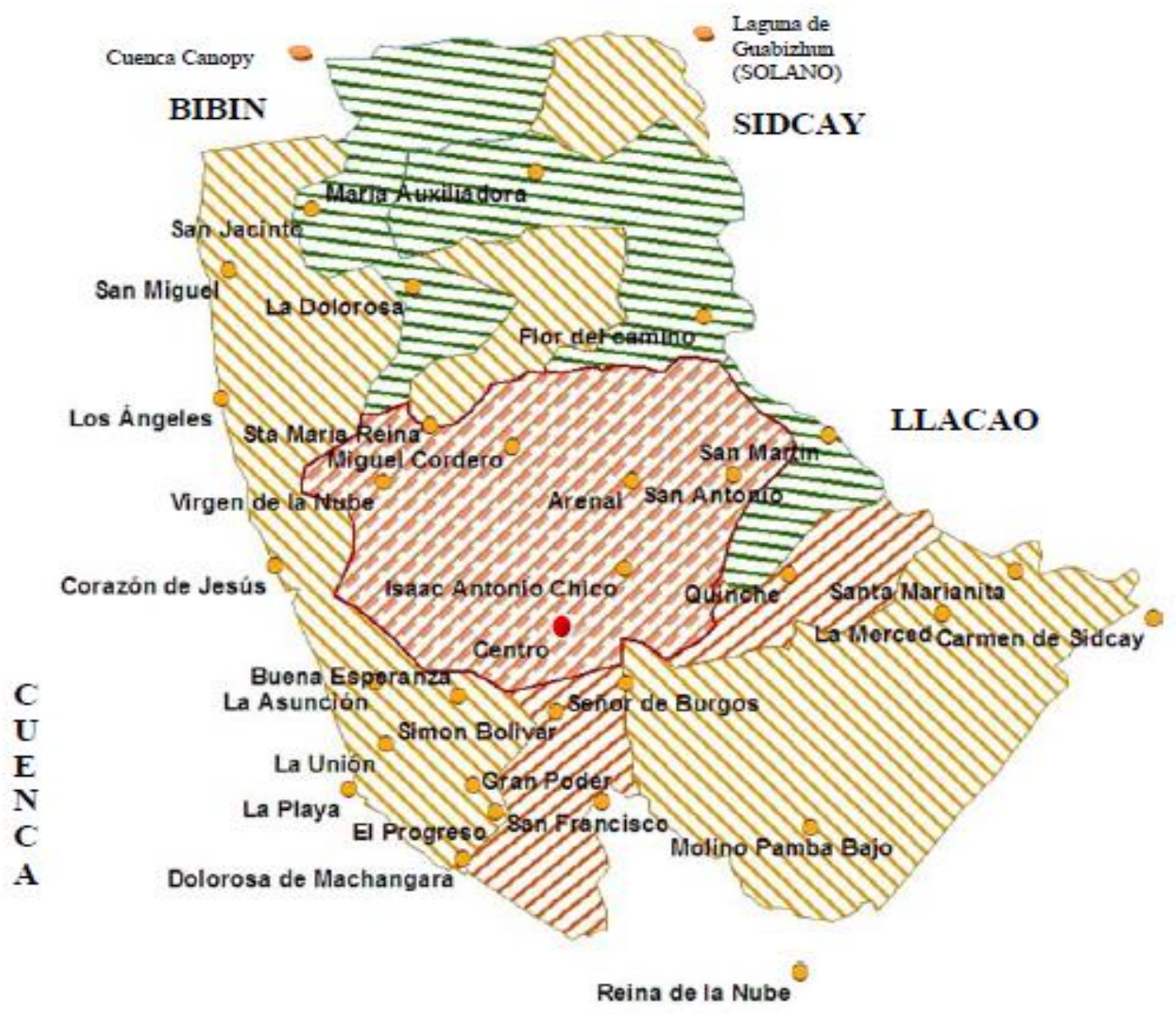

CUENCA

Figura 2. Mapa Político de la Parroquia de Ricaurte

La parroquia se caracteriza por su gran extensión territorial con una superficie y área de estudio de 1364,74 hectáreas y cuenta con 19.361 habitantes.

Su clima es templado con una temperatura promedio que oscila entre 15 y 18 grados promedio sobre los $2680 \mathrm{msnm}$.

Las principales atracciones de la parroquia son: su historia, cultura, tradiciones, gastronomía, la amabilidad de sus habitantes conjuntamente con una de las más nobles industrias que crecieron en la parroquia que es el tejido de los sombreros de paja toquilla ya que en la actualidad ocupa un lugar preponderante, siendo una artesanía de antaño que por su alta calidad es exportada hacia varios países del mundo. 
Disfruta también de grandes terrenos fértiles en los que se cultiva cualquier clase de hortalizas, cereales y plantas autóctonas como el eucalipto, capulí, el nogal y el maíz convirtiéndola dentro del ámbito agrícola como un granero para la ciudad de Cuenca. Ricaurte está conformado por 37 comunidades o barrios que se encuentran dentro de la parroquia de estudio que se los caracterizo por medio de la observación directa verificando el estado de los recursos y atractivos en tiempo real.

Tabla 1. Nombres de los Barrios y/o Comunidades de Ricaurte

\section{Barrio/Comunidad}

\begin{tabular}{rlll}
\hline $\mathbf{1}$ & El Ejecutivo & $\mathbf{2 0}$ & La Florida \\
$\mathbf{2}$ & La Dolorosa Loma de Machangara & $\mathbf{2 1}$ & Huajibamba La Merced \\
$\mathbf{3}$ & El Progreso & $\mathbf{2 2}$ & Isaac Chico \\
$\mathbf{4}$ & Los Pinos & $\mathbf{2 3}$ & Santa Marianita \\
$\mathbf{5}$ & Molino Pamba Bajo & $\mathbf{2 4}$ & EL Quinche \\
$\mathbf{6}$ & Jesús del Gran Poder & $\mathbf{2 5}$ & Virgen de la Nube \\
$\mathbf{7}$ & La Y & $\mathbf{2 6}$ & Corazón de Jesús \\
$\mathbf{8}$ & San Francisco & $\mathbf{2 7}$ & Santa Mariana Reina \\
$\mathbf{9}$ & La Asunción & $\mathbf{2 8}$ & EL Arenal \\
$\mathbf{1 0}$ & Simón Bolívar & $\mathbf{2 9}$ & San Martín \\
$\mathbf{1 1}$ & Buena Esperanza & 30 & San Antonio \\
$\mathbf{1 2}$ & Molinopamba Alto & 31 & Miguel Cordero \\
$\mathbf{1 3}$ & Señor de Burgos & 32 & Perpetuo Socorro \\
$\mathbf{1 4}$ & El Estadio & $\mathbf{3 3}$ & Flor del Camino \\
$\mathbf{1 5}$ & Centro Parroquial & $\mathbf{3 4}$ & San Miguel Los Ángeles \\
$\mathbf{1 6}$ & La Unión & 35 & San Jacinto \\
$\mathbf{1 7}$ & EL Cisne & 36 & La Dolorosa \\
$\mathbf{1 8}$ & El Carmen de Sidcay & $\mathbf{3 7}$ & María Auxiliadora \\
$\mathbf{1 9}$ & La Paz & & \\
\hline
\end{tabular}

Basándonos en el Plan de desarrollo y ordenamiento territorial de la parroquia de Ricaurte 2011-2030.

Hemos determinado que las principales actividades económicas que ayudan al desarrollo de la parroquia son: industria y manufactura con la elaboración de prendas de 
vestir y muebles, actividades de comercio al por mayor y menor, construcción, agricultura, ganadería y artesanías con sus manifestaciones en el campo de la carpintería, ebanistería, la pintura, tejidos del sombrero de paja toquilla y costura.

Análisis de la Accesibilidad e infraestructura

Según los datos obtenidos a través de la recolección de información por observación directa, hemos analizado la caracterización turística de la parroquia en la que se ha verificado la siguiente infraestructura de la oferta de servicios en alojamiento, alimentación, esparcimientos y otros servicios detallados a continuación en la siguiente tabla.

Tabla 2. Infraestructura de oferta de servicios

\begin{tabular}{llc}
\multicolumn{1}{c}{ Servicios } & \multicolumn{1}{c}{ Tipo } & Nro. \\
\hline Hosterías & alojamiento & 1 \\
Restaurantes & alimentación & 20 \\
Cafeterías & alimentación & 3 \\
Fuentes de soda & alimentación & 10 \\
Licoreras & alimentación & 6 \\
Quioscos de comida & alimentación & 8 \\
Parques recreacionales & esparcimiento & 5 \\
Instalaciones deportivas & esparcimiento & 5 \\
Agencias de viaje & servicios turísticos & 1 \\
Bancos & servicios bancarios & 5 \\
Cajeros automáticos & servicios bancarios & 7 \\
Centros de Salud & servicios de salud & 3 \\
Instituciones Educativas & educación & 16 \\
Policía Nacional & Emergencia & 1 \\
Cuerpo de Bomberos & Emergencia & 1 \\
Guardia Ciudadana & Emergencia & 1 \\
Pai de Ricaurte & Emergencia & 1 \\
Biblioteca Publica Ricaurte & Biblioteca & 1 \\
\hline
\end{tabular}

En cuanto a la infraestructura de los servicios básicos de transporte y la accesibilidad, se analizó que las distancias existentes hacia diferentes comunidades donde se encuentran algunos recursos y atractivos de interés no son tan apartados desde el centro parroquial o desde la ciudad de Cuenca. 
Tomando como referencia al más cercano con una distancia de 5 kilómetros desde Ricaurte y 12 kilómetros desde la ciudad de Cuenca. Existiendo algunas alternativas para llegar al sitio turístico como a través de buses, camionetas, bicicletas o caminando.

Las principales vías de acceso a la parroquia se encuentran asfaltadas, pavimentadas, lastradas y en buen estado, contando además con una señalización vial adecuada en el sector.

Por otro lado la comunidad Ricaurtense cuenta con transporte público conjuntamente con las estaciones o terminales de trasporte de buses, camionetas y taxis facilitando el desplazamiento adecuado de la población y personas que visitan la parroquia.

A continuación les presentamos en la siguiente tabla la descripción del transporte público terrestre que presta los servicios a la parroquia y sus comunidades.

Tabla 3. Transporte Público Terrestre

\begin{tabular}{|c|c|c|c|c|c|c|}
\hline \multirow{2}{*}{ Nombre de la Cooperativa } & \multirow{2}{*}{$\begin{array}{c}\text { Estación/T } \\
\text { erminal }\end{array}$} & \multicolumn{3}{|c|}{ Tipo de Transporte } & \multirow{2}{*}{$\begin{array}{l}\text { Frecuencia } \\
\text { del Servicio }\end{array}$} & \multirow{2}{*}{$\begin{array}{l}\text { Tipo de } \\
\text { Vehículo }\end{array}$} \\
\hline & & Local & Provincial & Nacional & & \\
\hline inea 100 & Terminal & $x$ & & & 5 minutos & buses \\
\hline Supertaxis $F$ & Estación & $x$ & & & $15 r$ & buses \\
\hline Radio Taxi Ricaurte & Estación & $x$ & $x$ & & $5-10 \mathrm{mi}$ & taxis \\
\hline Coop. Panamericana & Terminal & & $x$ & & 30 minutos & buses \\
\hline Transportes Mixto Pineda Peralta S.A. & Estación & $x$ & $x$ & & 5-10 minutos & camionetas \\
\hline
\end{tabular}

En cuanto a comunicación se refiere, existe servicio telefónico público y celular contando con 6 cabinas telefónicas y 6 cibercafés, asimismo existe oficina de correos para enviar cualquier tipo de encomiendas a otros países.

En lo que a sanidad se refiere, la parroquia cuenta con red de agua potable en un $95 \%$, tratando el agua con cloro en la fuente de distribución, teniendo como fuente principal de abasto la red pública ETAPA EP. La parroquia de igual forma en un $90 \%$ cuenta con sistema de alcantarillado y toda la población Ricaurtense elimina la basura a través del carro recolector para que este deseche en los botaderos o rellenos establecidos por la EMAC institución pública que vela por la sanidad de los habitantes. 
Igualmente en la parroquia existen establecimientos de salud como: parteras capacitadas, curanderos tradicionales, Sub-centro de salud, Consultorios privados, clínicas y farmacias que brindan servicio 24horas al día.

Otro punto importante es que el $100 \%$ de la población cuenta con energía eléctrica. Dentro de la gobernanza de la parroquia está el apoyo constante por parte de la llustre Municipalidad de Cuenca conjuntamente con la prefectura y algunas instituciones privadas como la Cooperativa Jep y el Banco del Pichincha en varios proyectos viales y culturas que sirven como aporte para el desarrollo y crecimiento de la población.

La comunidad tiene diferentes organizaciones como: La Junta Parroquial, Comité de Barrios, Organización de mujeres, organizaciones religiosas y clubes aportando cada una de ellas en diferentes actividades para el bienestar común de las comunidades de la parroquia.

Ricaurte como una comunidad receptora se dedican principalmente a las siguientes actividades económicas mencionadas en la siguiente tabla.

Tabla 4. Actividades Económicas de la Parroquia

\begin{tabular}{|c|c|}
\hline Actividad Económica & Porcentaje \\
\hline Agricultura, caza, avicultura, pesca & $22 \%$ \\
\hline Ganadería & $22 \%$ \\
\hline Construcción & $21 \%$ \\
\hline Industrias Manufactureras & $10 \%$ \\
\hline Artesanías & $7 \%$ \\
\hline Comercio, Transporte y Comunicación & $7 \%$ \\
\hline Servicios Comunales, sociales y personales & $6 \%$ \\
\hline Establecimientos Financieros & $5 \%$ \\
\hline Total & $100 \%$ \\
\hline
\end{tabular}

Las comunidades de la parroquia están siempre trabajando en mingas y asambleas comunitarias.

\section{Análisis de la Demanda:}

En cuanto a este análisis se ha observado que, si existe demanda de visitantes y excursionistas a este sector, ya que en un $20 \%$ realizan visitas de lunes a viernes, en 
un $35 \%$ los días sábados y en mayor porcentaje con un $45 \%$ las personas visitan la parroquia los días domingos. Considerando que la frecuencia de la demanda en un $50 \%$ es permanente todo el año y el otro $50 \%$ es estacional o en temporada.

\section{Demanda de la Parroquia Ricaurte}

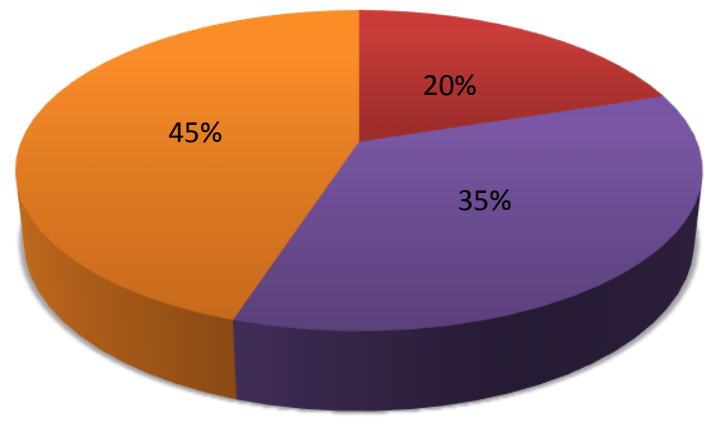

- Visitas de Lunes a Viernes Visitas los días Sábados Visitas los días Domingos

Figura 3. Demanda de la Parroquia de Ricaurte

A si mismo los visitantes prefieren conocer o viajar de manera independiente y no consideran que alguien les ayude con información valedera dentro del ámbito del turismo, ya que no existe un centro de información turística dentro de la parroquia. Por lo tanto se recomienda a las autoridades incrementar uno en corto plazo para medir la aceptación que pueden llegar a tener los sitios de interés turístico alrededor de la parroquia, puesto que la demanda que se posee es nacional, regional y local, realizando un gasto promedio de 25 dólares y las razones por las que visitan la parroquia es: por su gastronomía, por su gente y por sus fiestas tradicionales, haciendo el uso pertinente de los servicios en: restaurantes, quioscos de comida y hosterías.

\section{Análisis de la oferta:}

Presentamos el análisis en base a la ficha de caracterización de los recursos y atractivos establecidos en el inventario turístico, colocándolos asimismo de acuerdo a la 
categoría que cada atractivo consiguió, facilitando a los visitantes a conocer con el propósito de motivarles a realizar circuitos o excursiones por esta parroquia y a la vez puedan disfrutar del encanto rural dentro del entorno natural, cultural en el que nos muestran sus tradiciones en un solo espacio de la ciudad como es Ricaurte un encanto escondido.

\section{ATRACTIVOS NATURALES}

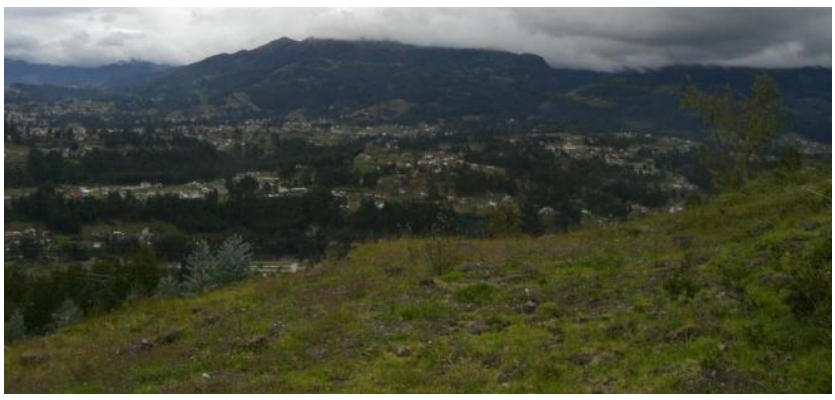

Loma de Bashun: Es una colina en donde se puede apreciar toda la ciudad de Cuenca, se la puede considerar como un escenario de completo relax. Esta se encuentra ubicada al noroeste de la parroquia, a tan solo 5 minutos de la plaza central de Ricaurte, desde el centro de Cuenca hasta el atractivo existen seis kilómetros. El atractivo cuenta con vías de acceso lastradas bien conservadas y se puede llegar en carro particular, bicicletas o a pie, cuenta con un clima templado de 18 grados centígrados, en su vegetación destaca los árboles de eucalipto y flores de las retamas, además se puede apreciar sembríos de maíz como muestra de la actividad económica a la que se dedica las comunidad.

Aquí en el verano se puede realizar el vuelo de las cometas actividad de distracción para niños, jóvenes y adultos ya que existe un espacio bastante amplio, relajado y el viento es el adecuado para esa actividad.

Otra actividad que se puede desarrollar dentro de esta área son campamentos por lo que es un área natural tranquila.

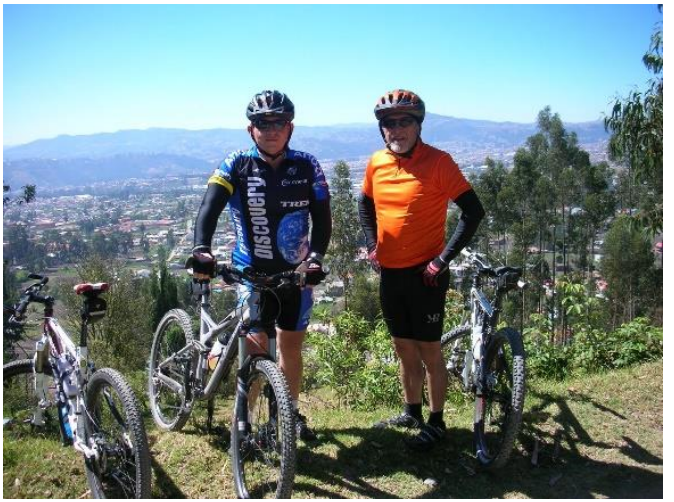

Mirador de Santa María: Este atractivo se encuentra en una colina a 9 kilómetros desde el centro de la ciudad, en este lugar se encuentra un santuario y una capilla en honor a la Virgen, por lo que muchos devotos y feligreses visitan el lugar para hacer oración, este lugar es un proyecto de ecoturismo por las plantas autóctonas 
que existen en el sector como: árboles de eucaliptos, sauces, retamas, pencos, árboles de capulíes, hierba, etc. y en cuanto a fauna se puede observar lagartijas, gorriones, mirlos, tórtolas, etc.

El Mirador está ubicado al oeste de la parroquia de Ricaurte a 10 minutos de la plaza central cuenta con vías asfaltadas y de lastre en buen estado, al que se puede acceder mediante carros pequeños, cuadrones, motos, bicicletas y a pie. En este lugar todos los años se realizan diferentes actividades como es: la procesión del rosario de la aurora a la virgen María, caminatas de peregrinación y la procesión del vía crucis.

En este sector se practica el ciclismo y motocross como actividades de aventura, descubriendo nuevas rutas dentro del entorno.

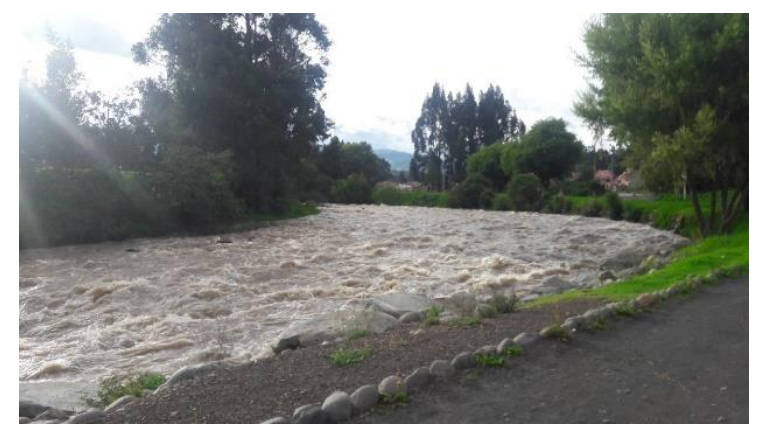

Barrió La Playa: Este barrio se encuentra ubicado al suroeste de la parroquia, aproximadamente a 6 kilómetros desde el centro de la ciudad y a tan solo 10 minutos del parque central de Ricaurte. En este barrio se puede disfrutar del Río que viene de San Miguel para formar el río Machangara de Cuenca.

Las vías de acceso a este sitio son muy fáciles y rápidas ya que cuenta con vías asfaltadas y lastradas señalizadas y en buen estado, por lo tanto se puede acceder con cualquier tipo de vehículo, bicicletas, motos, etc. Este atractivo es el más cercano al centro histórico de Cuenca.

Es las épocas de verano y fines de semana es un lugar muy accionado por los visitantes y excursionista para realizar paseos a la orilla del río, picnics, parrilladas, campamentos, hacer deporte, etc. entre familiares o amigos

Además se pueden realizar caminatas por los senderos existentes recorriendo a lo largo del río y en un entorno natural. 


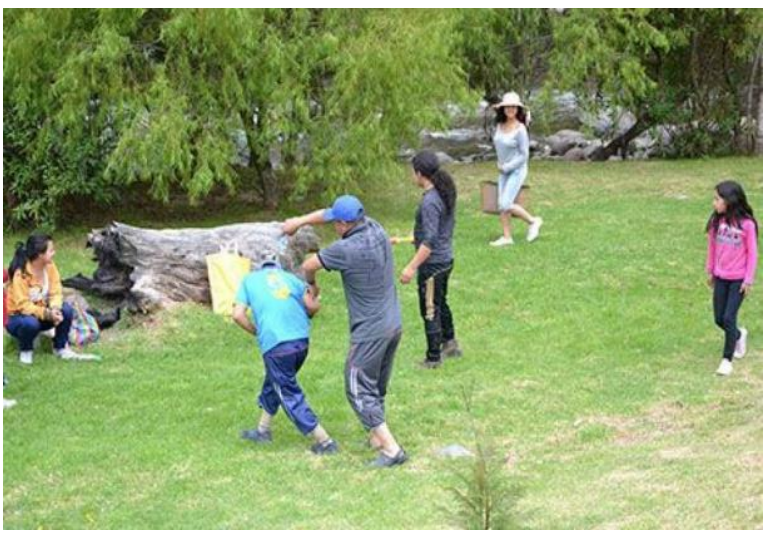

Barrió San Miguel: Se encuentra ubicado al noroeste de la parroquia de Ricaurte, aproximadamente a 15 minutos del centro parroquial y a 7 kilómetros desde el centro de la ciudad. A este lugar se puede llegar por medio de transporte privado o transporte público, ya que se cuenta con unidades de bus cada 15 minutos y se los puede

tomar en el centro de la ciudad de Cuenca, en el terminal terrestre o en el centro de la parroquia de Ricaurte.

En este lugar se pueden desarrollar algunas actividades como: excursiones, actividades de recreación en parques, paseos con amigos o familiares, campamentos, picnics, etc. Lugar en el cual además de su tranquilidad goza de una flora y fauna única del sector.

Este barrio se caracteriza por la amabilidad de su gente, su clima templado que permite a los visitantes los fines de semana, época de verano y carnaval realizar paseos y parrilladas junto a la orilla del río.

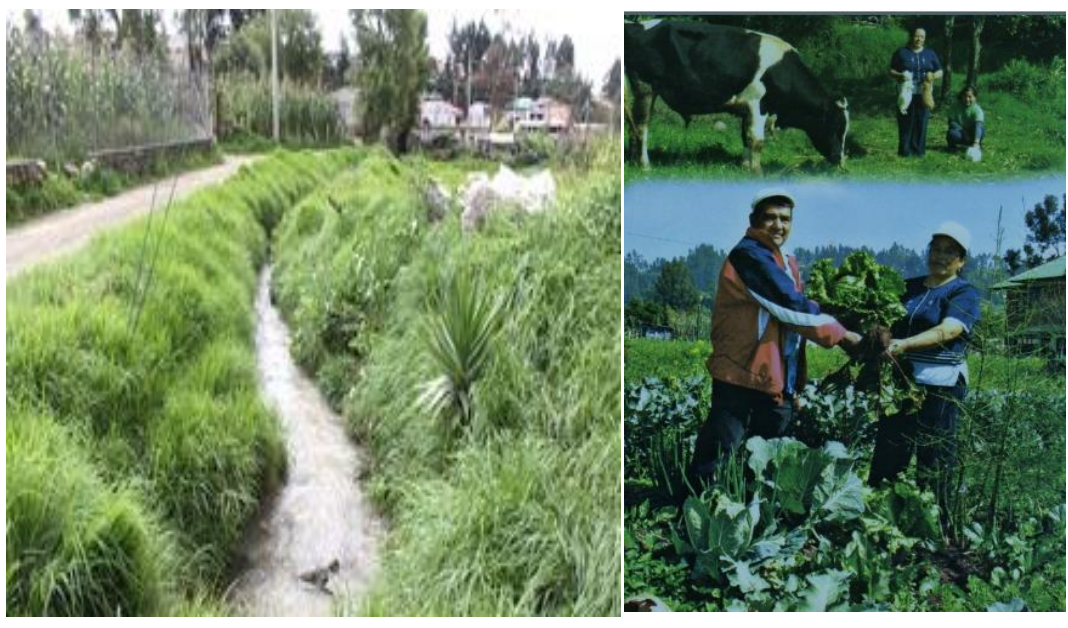

Canal de Riego: Este atractivo es muy importante en Ricaurte ya que tiene una historia y tradición de más de 100 años, cuando en las comunidades surgió la necesidad de contar con agua para poder regar los terrenos con sembríos, nació la idea de crear un canal de riego que beneficiaría a los cultivos desde Paluncay hasta Ricaurte. 
Desde ese entonces es que empieza a existir este canal de regadío para el mejor crecimiento de los cultivos de la parroquia, formando finalmente la sociedad de Riego de Ricaurte que dio sentido a lo importante que es trabajar en comunidad.

Este es un atractivo único que atraviesa toda la parroquia y beneficia de agua a los cultivos, por lo tanto Ricaurte por ser conocido como granero de Cuenca es indispensable que muestre el beneficio que brinda el agua en los cultivos a través del ejemplo que se ve reflejado en las flores, frutas, hortalizas, ganado y animales domésticos que conserva la parroquia.

\section{ATRACTIVOS CULTURALES}

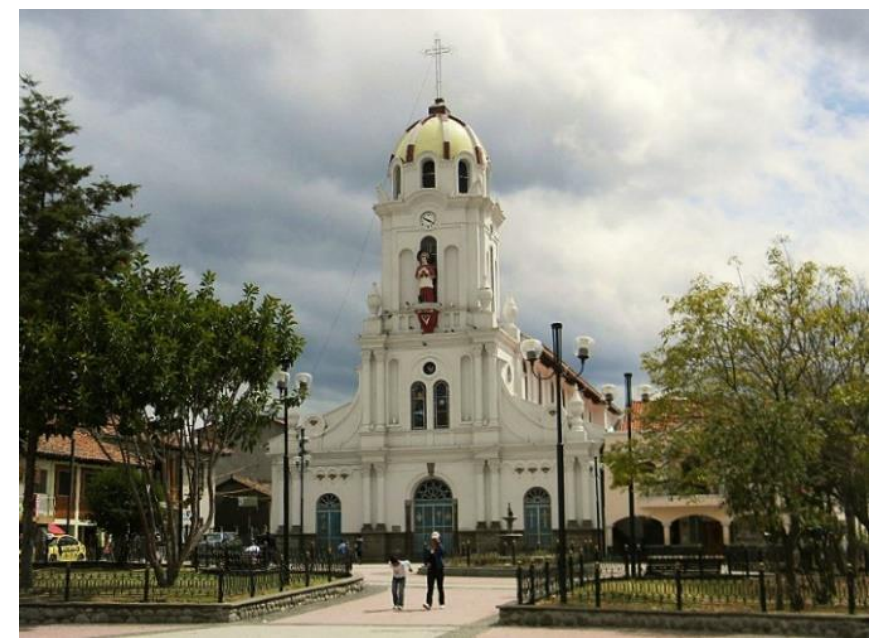

Iglesia San Carlos de Ricaurte: Ubicada y admirada en el centro parroquial por su belleza arquitectónica y su antigüedad, esta iglesia fue construida con cimientos de adobe y posteriormente con ladrillo, posee un estilo colonial, su cielo raso es de lato y el altar mayor fue elaborado en mármol donde posan los Santos que representan la parroquia como: La Virgen María y El Corazón de Jesús.

San Carlos Borromeo es el patrón de la parroquia y su escultura yace en un hermoso templo de edificación patrimonial rodeado de esculturas y pinturas realizadas por artistas de las primeras décadas del siglo XX.

Algo que se caracteriza en la construcción de este templo es que fue elaborada con la participación de todas las comunidades de Ricaurte en base a mingas demostrando de esa manera el amor hacia la parroquia y a la vez una muestra de manifestación de fe que trasciende de generación en generación.

Asimismo, la iglesia, su altar y la parroquia están dedicados al evangelista San Lucas y sus feligreses celebran las fiestas patronales sin ser titular, a la santísima virgen del Rosario el pueblo le rinde especial devoción teniéndola equivocadamente como su patrona. 


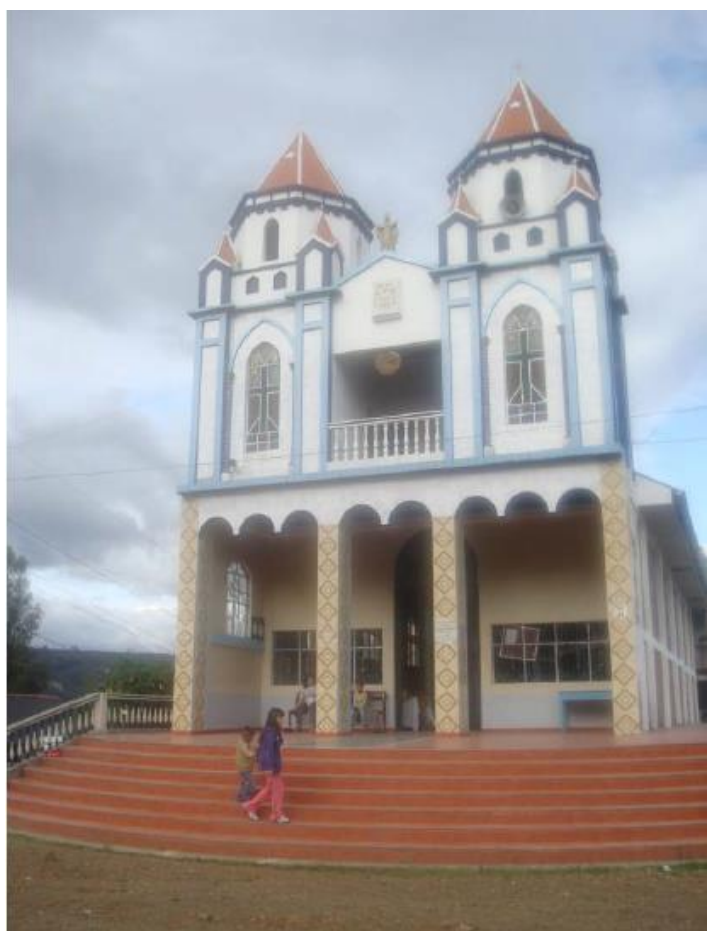

Huajibamba: Este atractivo se encuentra ubicado en la parroquia la Merced, al sur de la parroquia a tan solo 15 minutos de la plaza central de Ricaurte y a 9 kilómetros desde el centro de la ciudad de Cuenca.

Cuenta con un clima templado y la gente de la comunidad se dedica a la agricultura del maíz específicamente, el acceso a esta comunidad se lo puede hacer mediante transporte privado ya que el transporte público no presta los servicios en esta área.

Esta comunidad es muy religiosa por lo que cuenta con una iglesia en la que celebran misa a la virgen de la Merced todos los días sábados como muestra de su devoción. Asimismo hace aproximadamente 20 años se pudo encontrar vestigios arqueológicos que representaron un gran valor histórico en la comunidad como: oro, muestras de cerámicas y piezas históricas que fueron utilizadas por los antepasados para sus diferentes actividades cotidianas.

Estos hallazgos eran apreciables a simple vista, pero con el derrumbamiento de la loma se descendió gran parte de este sitio, ya que casi en un 50\% la loma desapareció llevándose un gran valor cultural del sector.

Actualmente ya no existen estos vestigios, pero la parte que se pudo rescatar de la loma queda como un mirador, pudiendo apreciar desde ahí las lagunas de oxigenación de la Ciudad de Cuenca, la autopista y gran parte de la comunidad de la Merced y Huajibamba. 


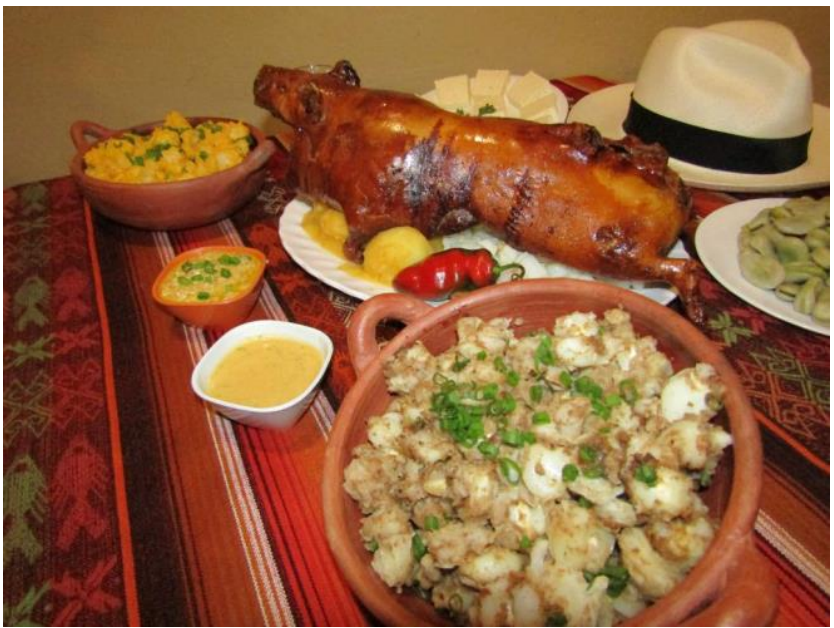

Gastronomía: La comida típica que se destaca en la parroquia es el cuy asado con papas, realizando cada año como muestra de la cultura tradicional, la fiesta del cuy con ají más grande, conocido por las personas que visitan la parroquia como el "Gran Festival del Cuy". Este magno evento se lo realiza en las fiestas de parroquialización que son en el mes de marzo y en el mes de noviembre el "Gran Banquete del Cuy" en honor al patrono "San Carlos Borromeo", empezando esta tradición en el año de 1999 como algo único de la parroquia.

Esta fiesta es preparada con meses de anticipación, ya que requiere de participación, colaboración y organización mancomunada por parte de los moradores de todas las comunidades, logrando que las festividades cumplan con las expectativas de miles de personas que visitan la parroquia en esas fechas con el propósito de degustar el prestigioso y delicioso cuy Ricaurtense.

La fama de este delicioso plato típico nos a invitado a conocer más de su historia e inicios para que se lo coloque como un banquete listo para degustar en la mesa de muchos comensales, ya que varias personas se dedican a la crianza del cuy con grandes galpones alrededor de la parroquia como: Déleg, El Guabo, La Dolorosa, San Miguel entre otros.

Por lo tanto Ricaurte cuenta con varios restaurantes de comida típica en los que no solo preparan el cuy asado sino también otras especialidades como: carnes asadas, pollo asado, pollo a I jugo, mote pillo, habas con queso, mote sucio, llapingachos entre otros.

Los restaurante más conocidos y tradicionales dentro de la parroquia son: Mi Escondite, Alcatraz, Cobayo, Rincón Lojanito, La Quebradita, entre otro, que fueron creados en la parroquia por emprendedores responsables, llenos de carisma y capaces de dar 
a conocer nuestra cultura y tradición culinaria por medio de la degustación de este plato típico.

Los precios del plato son accesibles para los clientes y varían desde 18 hasta 22 dólares dependiendo el tamaño del cuy.

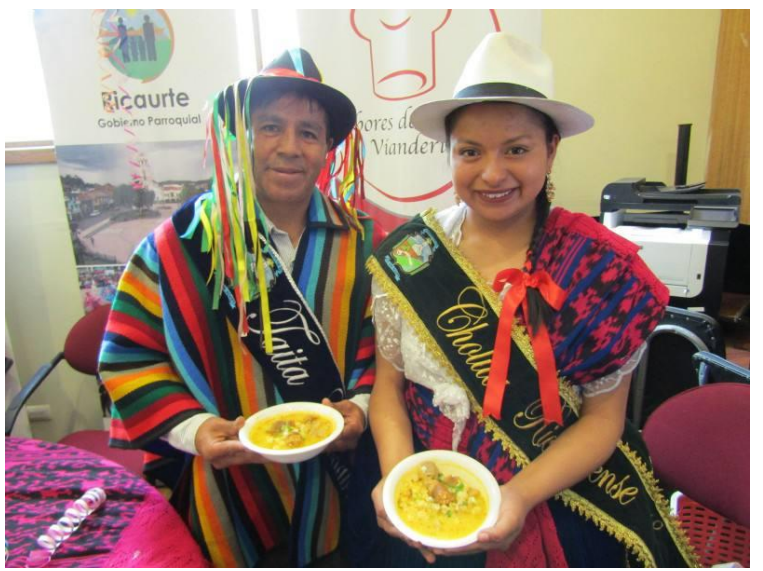

Fiestas Populares: Son actividades que caracterizan a la parroquia por mostrar su cultura y tradición a diferentes personas, por las festividades patronales y de fundación que se realizan en los meses de marzo y noviembre con una duración de siete días los cuales con la colaboración de las autoridades de Ricaurte y el apoyo de la Alcaldía de Cuenca, los representantes de los diferentes barrios, la policía nacional y otros miembros colaboradores, realizan eventos de carácter cultural, social, deportivo, religioso y de gala como es la elección de la Reina de Ricaurte y Cholita Ricaurtense.

Contando con la Belleza en la parroquia, es cuando se abren las festividades con un desfile cívico en el que participan todas las instituciones educativas de la parroquia con su banda de guerra y las diferentes comunidades con carros alegóricos que dan colorido a las festividades mostrando las tradiciones del entorno Ricaurtense.

Además se organizan shows artísticos con talentos nacionales y locales, comparsas, bailes folclóricos, juegos pirotécnicos con castillos, vacas locas y cuetes durante la noche de festividad.

Otra fiesta característica es la navidad, en esta época las calles de la parroquia se llenan de colorido con pequeños pastores, ángeles, cholitas, gitanas, vaqueros, papá Noel, entre otros.

Asimismo la fiesta del carnaval es muy típica en la parroquia en donde se reúnen en familia para compartir de la comida típica de la época y además de varias actividades recreativas entre amigos y familiares.

\section{Evaluación y Jerarquización}


De acuerdo a las características y aceptación que poseen estos atractivos dentro de la parroquia de Ricaurte, se ha podido determinar que la calidad cuenta con $50 \%$, ya que se considera que su entorno natural y cultural es de gran interés, pero debido a la falta de promoción turística no es visitada por personas extrañas a la parroquia, por lo tanto se llega a dar solo un turismo de tipo local, por ende lo que se pretende es dar a conocer el verdadero potencial turístico que nos ofrece la parroquia.

Ubicando en una jerarquía de tipo II, ya que cuenta con algunos rasgos llamativos capaces de captar la atención e interés de los visitantes siendo estos del mercado interno y receptivo llegando a la zona por otras motivaciones turísticas potenciales atrayendo al turismo fronterizo de esparcimiento.

\section{Competitividad de Ricaurte como destino turístico}

Por el momento no existe un margen competitivo en el campo turístico del sector de Ricaurte como destino turístico, ya que no se ha establecido una verdadera promoción turística del lugar logrando que esta sea aceptada por los turistas por medio de campañas publicitarias y promociones como tal.

FODA Matemático

\begin{tabular}{|c|c|c|c|}
\hline \multicolumn{4}{|c|}{ Matriz Estratégica de Factores Internos } \\
\hline \multicolumn{4}{|c|}{ Parroquia de Ricaurte } \\
\hline Factores & Peso & Calificación & $\begin{array}{l}\text { Calificación } \\
\text { Ponderada }\end{array}$ \\
\hline Debilidades & $50 \%$ & & \\
\hline 1. No contamos con una buena estratégia publicitaria & 0,1 & 2 & 0,2 \\
\hline 2. El tráfico en la página web no es la esperada & 0,1 & 2 & 0,2 \\
\hline 3. No contamos con transporte propio & 0,1 & 2 & 0,2 \\
\hline 4. No contamos con infraestructura & 0,1 & 1 & 0,1 \\
\hline 5. Cancelar viajes o tour por falta de acogida & 0,05 & 1 & 0,05 \\
\hline 6. La ubicación estratégica de la operadora en la parroquia & 0,05 & 1 & 0,05 \\
\hline Fortalezas & $50 \%$ & & \\
\hline 1. Es un proyecto innovador & 0,1 & 4 & 0,4 \\
\hline 2. Contaremos con recursos humanos capacitados & 0,15 & 4 & 0,6 \\
\hline 3. Dispondrá de tecnología & 0,1 & 3 & 0,3 \\
\hline 4. Ofrecer productos turísticos pioneros dentro del mercado & 0,15 & 4 & 0,6 \\
\hline 5. Atención personalizada a los turistas & 0,1 & 3 & 0,3 \\
\hline 6. Brindar servicios de calidad & 0,15 & 4 & 0,6 \\
\hline Totales & $100 \%$ & & 3,6 \\
\hline
\end{tabular}




\begin{tabular}{|c|c|c|c|}
\hline \multicolumn{4}{|l|}{ Matriz Estratégica de Factores Externos } \\
\hline \multicolumn{4}{|l|}{ Parroquia de Ricaurte } \\
\hline Factores & Peso & Calificación & $\begin{array}{l}\text { Calificación } \\
\text { Ponderada }\end{array}$ \\
\hline Amenazas & $50 \%$ & & \\
\hline 1. Falta de guías capacitados y registrados en el MITUR & 0,1 & 4 & 0,4 \\
\hline 2. Elevado número de competencias de agencias de viaje en el país & 0,1 & 4 & 0,4 \\
\hline 3. Disminución de ingresos económicos en temporadas bajas & 0,05 & 3 & 0,15 \\
\hline 4. Fuertes campañas publicitarias por agencias mayoristas & 0,1 & 3 & 0,3 \\
\hline 5. Tramites demorados para obtener los permisos de funcionamiento & 0,05 & 4 & 0,2 \\
\hline 6. La falta de infraestructura vial & 0,1 & 4 & 0,4 \\
\hline Oportunidades & $50 \%$ & & \\
\hline 1. Extenso desarrollo turístico de la agencia en el país & 0,1 & 4 & 0,4 \\
\hline 2. Poder ofrecer servicios turísticos de recreación, capacitación y formación a estudiantes & 0,05 & 3 & 0,15 \\
\hline 3. Introducir nuevos productos turisticos de fácil acceso y económicos & 0,1 & 4 & 0,4 \\
\hline 4. Se contara con alianzas estratégicas con hoteles y restaurantes & 0,1 & 4 & 0,4 \\
\hline 5. Introducir productos turísticos por medios virtuales & 0,1 & 3 & 0,3 \\
\hline 6. Aumento de desplazamiento de los turistas en feriados y fines de semana & 0,05 & 3 & 0,15 \\
\hline Totales & $100 \%$ & & 3,65 \\
\hline
\end{tabular}

\section{Líneas Estratégicas de Desarrollo}

Después de haber elaborado el instrumento del cuestionario y logrado analizarlo, se verifica que el rango de edad de los turistas que visitan la ciudad de Cuenca mayormente se encuentran dentro de las edades de 40 a 49 años con un porcentaje del $41 \%$ y seguidamente entre las edades de 30 a 39 años con un porcentaje del $27 \%$ considerando que estos son los porcentajes más altos, se puede decir que los turistas que visitan cuenca están en una edad madura logrando obtener su solvencia de manera independiente al momento de decidir realizar un viaje

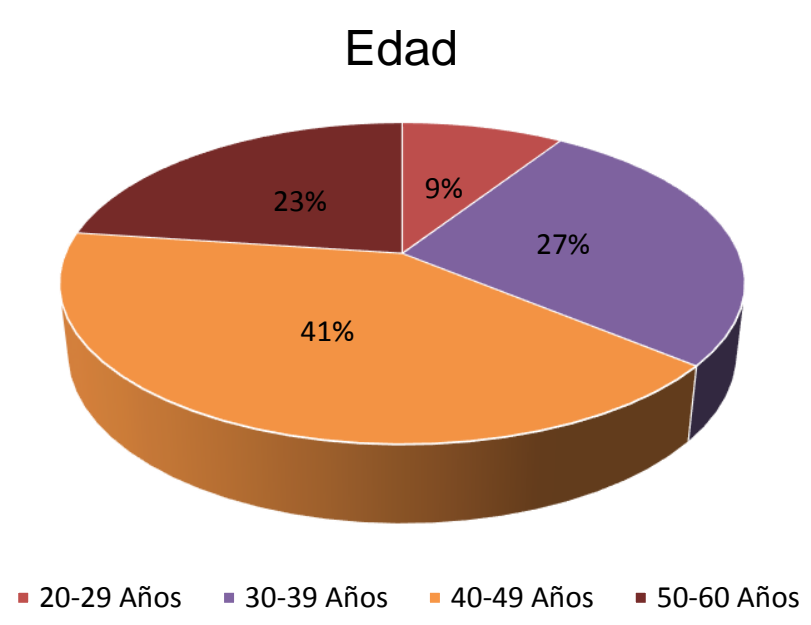

Figura 4. Edades de Turistas 
Asimismo, se puede observar diferentes tipos de nacionalidades que visitan la provincia para realizar turismo, tomando en cuenta que el porcentaje mayor con un $21 \%$ son turistas Norte Americanos dándonos posteriormente apertura con un 19\% los turistas Europeos, seguidos de los Argentinos con un 16\%.

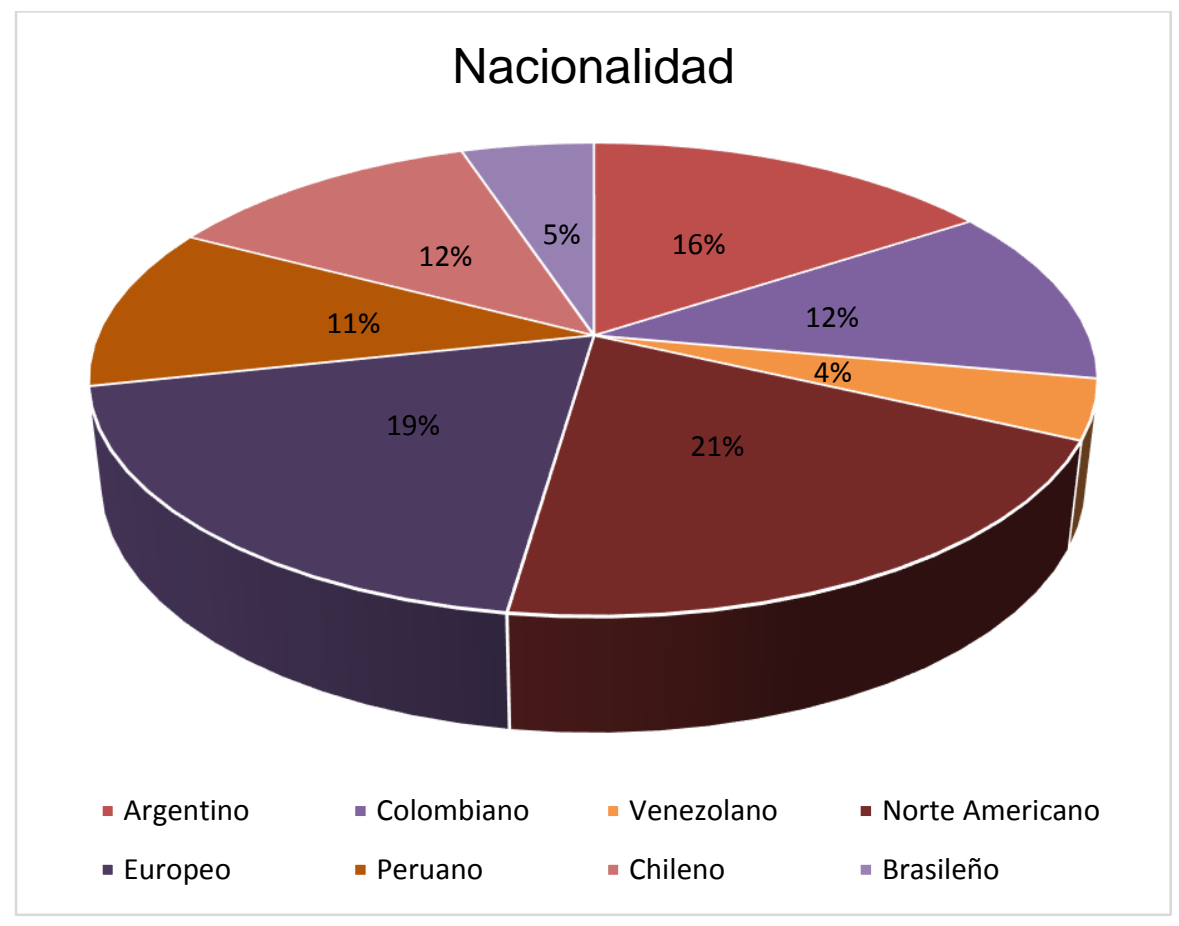

Figura 5. Nacionalidad de turistas que visitan Azuay, Ecuador

Posteriormente al momento de realizar un viaje el turista prefiere incursionar en el turismo cultural y ecoturismo en un $16 \%$ y el turismo de aventura en un $15 \%$ siendo estos los de mayor porcentaje en el análisis presentado. 


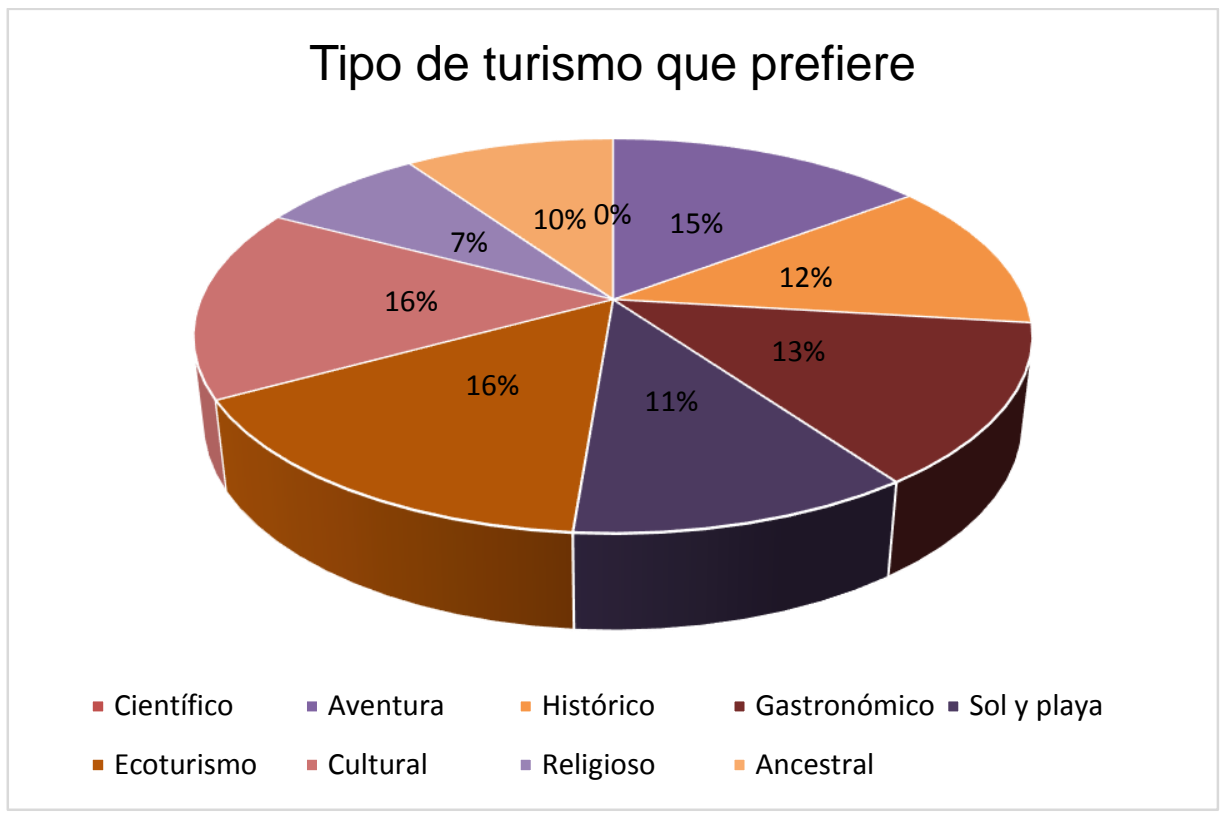

Figura 6. Tipos de Turismo que prefieren

Al momento de planificar un viaje el turista considera realizar ciertas actividades de turismo durante su viaje, por lo que se a analizado que las preferencias dentro de las actividades que más les gusta desarrollar a los turistas son las excursiones arqueológicas con un $48 \%$ y las visitas guiadas con un $22 \%$

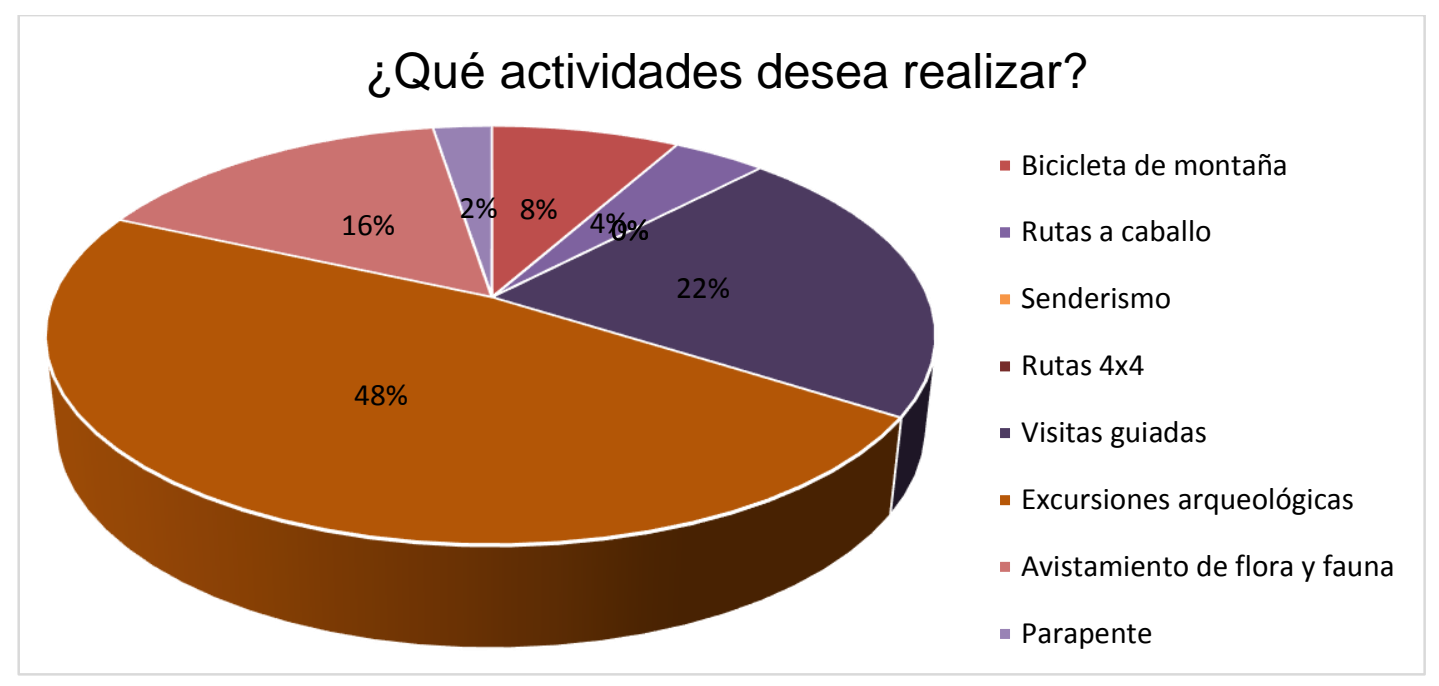

Figura 7. Actividades que les gusta realizar a los turistas 
Podemos considerar que a los turistas les gusta viajar tanto en temporada baja que conforman los meses entre julio y diciembre pero también en temporada alta que estarían los meses entre enero y junio obteniendo un $50 \%$ en cada temporada después de haber realizado el respectivo análisis.

\section{En que temporada le gusta viajar mas}

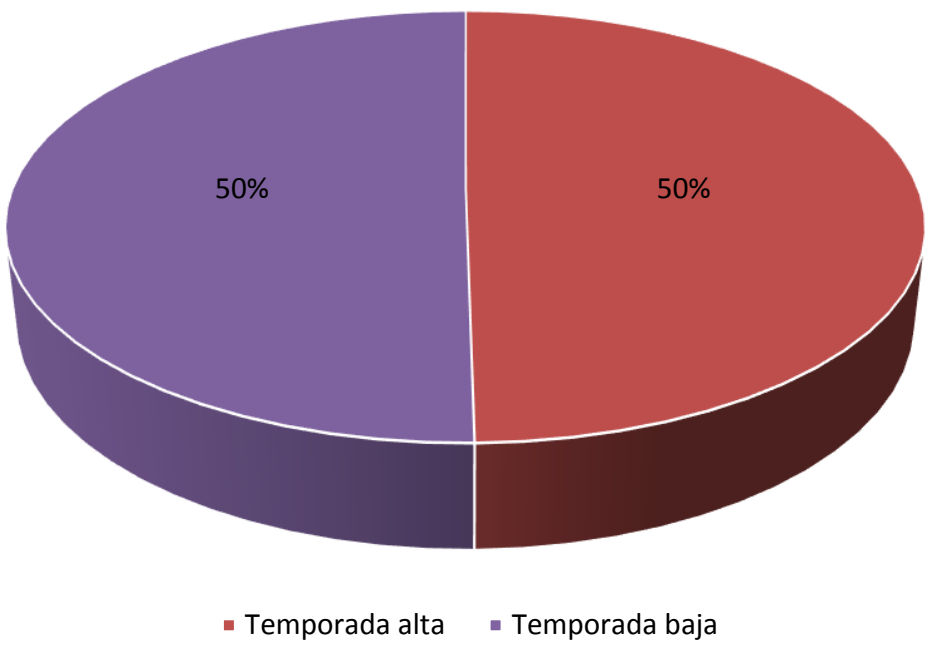

Figura 8. Temporada de viaje

En base a la entrevista realizada al Ing. Edwin Rene Idrovo Mogrovejo, Director de Planificación Turística del GAD Municipal de Nabón con la finalidad de determinar el potencial turístico de la parroquia de Ricaurte logrando el desarrollo turístico, social y económico de la misma, pudimos obtener información muy valedera tomando en cuenta sus criterios en base al conocimiento y experiencia que el adquiere dentro del área turística, indicándonos que uno de los puntos clave para la integración de las comunidades es la asociatividad solidaria, pueden ser de hecho o de derecho, lo importante es que las comunidades mediante asociaciones encuentren una ventaja competitiva frente a la competencia, de esta manera potenciar sus productos de manera organizada y ordenada dando un servicio turístico eficiente y de calidad.

De igual manera, como es de conocimiento el sector turístico es el negocio de más rápido crecimiento y uno de los más rentables, por lo tanto, cada comunidad tiene que 
ser competitiva, no en precios de servicios, sino en calidad y diversidad del producto de esta manera dinamizara económicamente cada sector productivo.

Por lo tanto, para brindar un servicio de calidad y eficaz, la gente encargada en ofrecer los servicios turísticos deben estar capacitados, con altos niveles de conocimiento en atención al cliente, fidelización del cliente, higiene, salubridad, organización y planificación para de esta manera determinar clientes potenciales que demandaran el servicio, y a la vez mantener a los clientes establecidos.

Logrando dentro del ámbito turístico una propuesta innovadora para promocionar la parroquia de Ricaurte a nivel nacional e internacional a través de programas y proyectos que busquen coordinar acciones con operadores turísticos de la región para promover la práctica del turismo con altos estándares de calidad y seguridad. Asimismo la implementación de una marca comunitaria que genere una imagen positiva de la parroquia, donde recoja los atractivos turísticos y potencialidades del territorio en cuanto a su diversidad cultural y su gastronomía autóctona para promocionar el desarrollo turístico de la parroquia a través de la utilización de tecnologías de la información, las comunicaciones y demás medios tradicionales de manera que se logre posicionar en la mente de los visitantes nacionales y extranjeros, utilizar los medios publicitarios existentes en plataformas virtuales, tales como las redes sociales y el sitio web de la parroquia, donde se publicarán videos de la región, historias o casos de éxito (donde se exponen experiencias positivas de los visitantes a la parroquia) para obtener mejores resultados de posicionamiento y ofrecer a los usuarios información concisa acerca de los atractivos turísticos del territorio.

Las características con las que debe contar un centro de recreación o esparcimiento turístico para brindar un servicio de calidad al turista es brindando atención personalizada y direccionada para información correcta a los consumidores, personal capacitado, respuesta inmediata a necesidades, óptimos procesos en la cadena de valor con los distintos grupos de interés, comunicación clara y espontanea de los servicios ofrecidos y no generar publicidad engañosa. 
Para mejorar el servicio de los establecimientos turísticos en la parroquia se ve oportuno desarrollar programas de levantamiento de Catastro y categorización de los establecimientos turísticos con apoyo del Ministerio de Turismo y los entes públicos competentes, para tener certeza de la calidad del establecimiento turístico según estándares definidos por las dependencias reguladoras. Además, incentivar a los propietarios a adecuar, remodelar, los establecimientos turísticos, a cambio de publicidad efectiva en medios de comunicación tecnológicos y tradicionales con el apoyo de la empresa pública y privada.

\section{CONCLUSIONES}

En el desarrollo de la investigación se ha podido analizar cada uno de los recursos y atractivos tanto naturales como culturales, simultáneamente con la infraestructura de la parroquia y los servicios turísticos que conlleva los elementos del sistema turístico de un destino, en el cual se ha verificado que Ricaurte es afortunado por las riquezas que posee dentro de su entorno.

Logrando que este proceso nos ayude en el desarrollo dentro del ámbito turístico buscando el bienestar social, económico y cultural de la comunidad Ricaurtense.

Los resultados manifiestan que Ricaurte es una parroquia competitiva que cuenta con la oferta necesaria para que los turistas se interesen por visitarla, pero con el apoyo incondicional de los moradores de cada comunidad o barrio se incentivaran programas de capacitación dentro de establecimientos que brinden servicios turísticos para mejorar su atención. Logrando de esta manera promocionar la identidad que caracteriza a Ricaurte, por medio de una campaña publicitaria en medios de comunicación, internet, páginas web, operadoras de turismo, entre otras.

Buscando asimismo que la demanda se incorpore en nuevas actividades de turismo alternativo, turismo de aventura, turismo gastronómico, turismo comunitario, entre otros, logrando así una mayor afluencia por parte del público objetivo dentro de los diferentes barrios o comunidades durante todo el año.

Y así se logrará que se desempeñen las estrategias establecidas para el desarrollo de una buena planificación turística en la parroquia de Ricaurte. 


\section{REFERENCIAS CONSULTADAS}

1. Alcocer, L. J. (2013). Competitividad en el sector turistico: una revisión de la literatura. Lebret, 1-21.

2. Aldana, J., \& Piña, J. (2017). Calidad del servicio prestado al cliente por los instructores de gimnasios. Revista Arbitrada Interdisciplinaria Koinonía, 2(3), 172-197. Recuperado de http://fundacionkoinonia.com.ve/ojs/index.php/revistakoinonia/article/view/59/46

3. Blanco, M. (2008). Guía para la elaboración del plan de desarrollo turistico de un territorio. Asesores en turismo Peru, 1-45.

4. Boullón, R. (2006). Planificación del espacio turistíco. México: Trillas.

5. Idrovo, M. E. (2019). Marketing Estratégico turístico para la provincia del AzuayEcuador. Visionario Digital, 235-256.

6. Larrea, E. (2019). Proyección de Turismo para Ecuador en el 2018. Entorno Turistico, 1-30.

7. Ministerio de Turismo. (1 de Febrero de 2019). Ministerio de Turismo. Obtenido de Ministerio de Turismo: https://www.turismo.gob.ec/el-turismo-en-ecuadorcuenta-con-cinco-hitos-en-2019/

8. Ministerio de Turismo, Ecuador. (2012). Plan estratégico de desarrollo de turismo sostenible para Ecuador: Plan de Tour 2020. Plan de Tour 2020, 1-106.

9. Ponce, T. H. (2006). La matriz FODA una alternativa para realizar diagnóstico ydeterminar estrategias de intervención en las organizaciones productivas y sociales. Contribuciones a la económia, 1-16.

10. Ramón Ochoa, M. d., Erazo Álvarez, J. C., Narváez Zurita, C. I., \& Matovelle Romo, M. M. (2019). Gestión del capital intelectual en las cooperativas de ahorro y crédito de la ciudad de Loja aplicando el modelo Servqual. Visionario Digital, 297.

11. Ricaurte, Q. C. (2009). Manual para el diagnóstico turístico local. Guayaquil: Escuela Superior Politecnica del litoral.

12. Sancho, A. (2017). Introducción al Turismo, OMT. Soporte docente, 43-46. 
13. Siles, L. D. (2016). Competitividad de los destinos turisticos. Repositorio Dlgita, $1-175$.

14. Vargas, F. T. (2010). Metodología para el diagnóstico de la capacitación en el turismo sostenible con enfoque de organización que aprende. Revista de investigación en turismo y desarrollo local, 1-18.

\section{REFERENCES CONSULTED}

1. Alcocer, L. J. (2013). Competitiveness in the tourism sector: a review of the literature. Lebret, 1-21.

2. Aldana, J., \& Piña, J. (2017). Quality of service provided to the client by gym instructors. Interdisciplinary Arbitrated Review Koinonía, 2 (3), 172-197. Recovered from http://fundacionkoinonia.com.ve/ojs/index.php/revistakoi$\underline{\text { nonia/article/view/59/46 }}$

3. Blanco, M. (2008). Guide for the development of the tourist development plan of a territory. Tourism consultants Peru, 1-45.

4. Boullón, R. (2006). Tourism space planning. Mexico: Threshing.

5. Idrovo, M. E. (2019). Strategic Tourism Marketing for the province of AzuayEcuador. Digital Visionary, 235-256.

6. Larrea, E. (2019). Tourism Projection for Ecuador in 2018. Tourist Environment, 1-30.

7. Ministry of Tourism. (February 1, 2019). Ministry of Tourism. Obtained from the Ministry of Tourism: https://www.turismo.gob.ec/el-turismo-en-ecuador-cuentacon-cinco-hitos-en-2019/

8. Ministry of Tourism, Ecuador. (2012). Strategic plan for the development of sustainable tourism for Ecuador: 2020 Tour Plan. 2020 Tour Plan, 1-106.

9. Ponce, T. H. (2006). The SWOT matrix is an alternative to diagnose and determine intervention strategies in productive and social organizations. Contributions to the economy, 1-16.

10. Ramón Ochoa, M. d., Erazo Álvarez, J. C., Narváez Zurita, C. I., \& Matovelle Romo, M. M. (2019). Management of intellectual capital in credit unions in the city of Loja applying the Servqual model. Digital Visionary, 297. 
11. Ricaurte, Q. C. (2009). Manual for local tourist diagnosis. Guayaquil: Coast Polytechnic High School.

12. Sancho, A. (2017). Introduction to Tourism, OMT. Teaching support, 43-46.

13. Siles, L. D. (2016). Competitiveness of tourist destinations. Dlgita Repository, $1-175$.

14. Vargas, F. T. (2010). Methodology for the diagnosis of training in sustainable tourism with an organizational approach that learns. Journal of research in tourism and local development, 1-18.

C2019 por el autor. Este artículo es de acceso abierto y distribuido según los términos y condiciones de la licencia Creative Commons Atribución-NoComercial-Compartirlgual 4.0 Internacional (CC BY-NC-SA 4.0) (https://creativecommons.org/licenses/by-nc-sa/4.0/). 